\title{
Discussions Report: Reorganization of Companies
}

\author{
by
}

\section{LENA SCHMIDT ${ }^{1}$}

The importance of Chapter 13 - concerning the reorganization of companies was already pointed out in the morning session. Therefore, a large number of participants attended the workshop, which was chaired by Martin Winner (University of Economics and Business Vienna).

In his initial speech, Christoph Teichmann (University of Wuerzburg) introduced the participants to the main content of Chapter 13 particularly focusing on mergers, divisions and the cross border transfer of the registered office of private and public companies. He highlighted that the main goal of the group in this chapter was to combine the existing acquis communautaire concerning the restructuring of companies and to add the missing parts, mostly already provided by the European Court of Justice. In accordance with the European directives, the EMCA therefore contains provisions regulating domestic (Directive 78/855/EEC, now 2011/35/EU) and cross-border mergers (Directive 2005/56/EC), as well as domestic divisions (Directive 82/891/EEC). Next to these methods of re-organization, the group added provisions concerning the cross-border division and the cross-border transfer of the registered office.

After a short presentation on the basic configuration of restructurings under the EMCA, Teichmann focused on the creditor protection provisions contained therein. In the case of a domestic/cross-border merger or division, creditor protection is mainly ensured by the necessity of an expert's report. This report - for which the independent expert will be held liable (Sec. 20 EMCA) - has to state whether the creditors will be sufficiently protected after the merger or division. In consequence, the creditors may only claim adequate security if the expert comes to the conclusion that the financial situation of the merging companies requires additional safeguards. In cases of a transfer of the registered office the creditors are usually not affected. Therefore, the EMCA group decided to use a different model of creditor protection which gives the creditors the right to credibly demonstrate that due to the transfer, the satisfaction of their claim is at stake.

The $1^{\text {st }}$ discussant, Paulo Olavo Cunha (Catholic University of Portugal) began with some general comments on the EMCA. Regarding Chapter 13

1 PhD Candidate, University of Würzburg. 
and the domestic and cross-border reorganization in form of a merger, he focused on the protection of shareholders and creditors. He therefore distinguished between the direct protection of the shareholders (e.g. Sell-out right (of dissenting shareholders), Sec. 17 and Sec. 30) and creditors (e.g. Possibility to claim adequate security, Sec. 13 and 28) and the indirect protection of the stakeholders interests in form of examination, reports and the courts control. Regarding the possibility of the courts to protect the stakeholders' interests, Cunha suggested a non-court solution which instead makes recourse to a competent administrative authority (e.g. the registrar).

The $2^{\text {nd }}$ discussant Sebastian Mock (University of Hamburg) concentrated his presentation on the Scheme of Arrangement, which is included in Sec. 2-4 of Chapter 13. First he raised the issue as to why this voluntary agreement between the company and its creditors and/or shareholders to restructure the company outside insolvency proceedings was included in the EMCA at all. Referring to the aims of the EMCA as a model act, he argued that the scheme of arrangement had to be implemented in the EMCA because of its success in the UK and Ireland. Apart from this, the scheme of arrangement is also seen as an attractive and flexible tool for the restructuring of companies outside of these countries. He therefore stated a list of advantages and disadvantages of the scheme of arrangement. Concerning the protection of the members and creditors in case of a scheme of arrangement, Mock illustrated that the major aspect in this regard is the compulsory ex post sanction of the court.

In the discussion at the end of the workshop, the debates focused on the following topics:

(1) The foremost discussed aspect was the protection of creditors and minority shareholders included in Chapter 13. Concerning the minority shareholders, the question as to whether a sell-out right applies to all or to only certain types of mergers was a particular point of discussion. The participants agreed, that the EMCA has to specify in which re-organization forms and under which conditions a sell-out right must be provided to the minority shareholders.

(2) Two questions arose concerning the cross-border transfer of the registered office:

The first question focused on the consequences in the applicable law in case of a cross-border transfer of the registered office. Teichmann underlined that no conclusion was found concerning the basic distinction between the real-seat theory and the incorporation theory. Therefore the transfer of the registered office includes no statement on the applicable law.

Some participants wondered if the EMCA seeks to provide a cross-border transfer of the registered office to countries outside of the European Union. In 
regard to this issue the EMCA members admitted that this scenario had not been considered but will be discussed in the following revision after this conference.

(3) Regarding the scheme of arrangement, the discussion focused on the question as to whether the compulsory ex-post sanction of the court provides the necessary level of protection. Also, a participant from the UK added some comments from the view of a country which has dealt with this type of agreement for several years. She pointed out that the experience with the scheme of arrangement revealed that it is often used to reorganize the equity capital and not only in cases of insolvency. She also indicated that the UK had a lot of problems with the "headcount-test" and suggested to drop that aspect for the EMCA. 